\title{
Processos cognitivos na leitura inicial: relação entre estratégias de reconhecimento de palavras e alfabetização
}

Sara Mourão Monteiro'

Magda Soares'

\begin{abstract}
Resumo
0 conhecimento das correspondências grafema-fonema fornece um sistema mnemônico que contribui para a formação dos leitores iniciantes, favorecendo o desenvolvimento da fluência e da compreensão na leitura. Entretanto, muitas crianças apresentam dificuldade no processo de mapeamento automático da escrita das palavras e de sua pronúncia e podem necessitar de muito mais treino para atingir um nível normal de aprendizagem da leitura. Esta pesquisa examinou as estratégias de reconhecimento de palavras escritas manifestadas por crianças que enfrentam dificuldades no processo de alfabetização, em um teste de leitura controlado por critérios linguísticos relacionados às propriedades das palavras, tais como a estrutura interna da sílaba e os valores de grafemas independentes e dependentes de contexto na composição das palavras. A partir da caracterização das estratégias usadas pelas crianças, buscou-se saber em que medida elas impedem a identificação da pronúncia e do significado da palavra escrita. Concluiu-se que as dificuldades das crianças estão relacionadas a estratégias de leitura de palavras que evidenciam uma dissociação entre conhecimento das letras e desenvolvimento da consciência fonológica. Constatou-se, ainda, que o atraso no processo de aprendizagem dos alunos pode ter relação com o pouco conhecimento das regras de correspondências letra-som e com a difıculdade do mecanismo de decodifıcação na análise de estruturas silábicas não canônicas.
\end{abstract}

\section{Palavras-chave}

Alfabetização - Aprendizagem inicial da leitura - Leitura de palavras.
I- Universidade Federal de Minas Gerais, Belo Horizonte, MG, Brasil. Contatos: mourao.sara@gmail.com; mbecker.soares@terra.com.br 


\title{
Cognitive processes in initial reading: the relationship between word recognition strategies and literacy
}

Sara Mourão Monteiro'

Magda Soares

\begin{abstract}
The knowledge of grapheme-phoneme correspondences provides a mnemonic system which contributes to the training of beginning readers, favoring the development of reading fluency and comprehension. However, many children have difficulty in the process of automatic mapping of the writing and pronunciation of words and may need much more training to achieve a normal level of reading acquisition. This research has examined the strategies for recognizing written words expressed by children facing difficulties in literacy process in a reading test controlled by linguistic criteria related to the properties of words, such as the internal structure of syllables and the values of context-dependent and independent graphemes in the composition of words. From the characterization of the strategies used by the children, We sought to determine to what extent such strategies prevent the identification of the pronunciation and meaning of written words. It was concluded that children difficulties are related to strategies for reading words which demonstrate a dissociation between the knowledge of letters and the development of phonological awareness. It was also found that the delay in the learning process of students may be related to poor knowledge of the letter-sound correspondence rules and to the difficulty of the decoding mechanism in the analysis of non-canonical syllable structures.
\end{abstract}

\section{Keywords}

Literacy - Initial learning of reading - Word reading.

I- Universidade Federal de Minas Gerais, Belo Horizonte, MG, Brasil. Contacts: mourao.sara@gmail.com; mbecker.soares@terra.com.br 
Nas últimas décadas, especialistas na área da leitura, em particular do campo da psicologia cognitiva, têm enfatizado a relação entre leitura de palavras e compreensão de textos, o que explica a significativa produção de pesquisas que abordam o reconhecimento da palavra escrita como um importante foco de investigação sobre o processo de leitura.

Ao ler, o leitor desenvolve duas atividades fundamentais: identifica as palavras que compõem o texto e constrói significados para o que lê. No entanto, para realizar a leitura de forma eficiente, ele não pode dispensar atenção a essas duas atividades na mesma medida. A construção do significado se baseia em reunir as palavras lidas em unidades significativas de pensamento, permitindo que o leitor faça inferências, relacione informações prévias com as apresentadas no texto e analise criticamente o significado construído (PIKULSKI; CHARD, 2005). Outro aspecto importante da construção de significados é o fato de ela se dar por meio de um processo condicionado pelas práticas concretas de leitura, tornando-a dependente de circunstâncias sociais e culturais implicadas em sua realização. Podemos dizer, dessa forma, que não há possibilidade de a construção do significado se dar de forma automatizada.

Por outro lado, a identificação de palavras pode ser realizada de forma rápida e fácil, com automatismo, não requerendo muito esforço e atenção do leitor. Segundo Samuels (2006), o reconhecimento automático das palavras é necessário para permitir ao leitor centrar sua atenção na compreensão do texto, o que favorece a fluência que, no Literacy Dictionary (HARRIS; HODGES, 1995), é definida como capacidade de reconhecimento de palavras que leva à compreensão. Uma pesquisa com crianças brasileiras efetuada por Corso e Salles (2009, p. 32) conclui que "certa capacidade de leitura de palavras é necessária para ler um texto com compreensão e [...] falhas na leitura de palavras prejudicam a compreensão adequada do texto".

Com base nesses pressupostos teóricos, tem se dado muito destaque, na discussão sobre práticas de ensino da língua escrita, ao desenvolvimento das estratégias de reconhecimento de palavras que podem contribuir para a formação de leitores fluentes.

\section{O processo de reconhecimento de palavras}

A leitura de palavras ocorre quando o leitor coloca em ação um sistema de reconhecimento que integra três componentes da palavra escrita: o ortográfico - a forma escrita da palavra -, o fonológico - forma falada da palavra - e o semântico - significado da palavra (PLAUT, 2005).

Durante a leitura, esses três componentes podem ser acionados pelo leitor de diferentes formas. Uma delas, conhecida como via fonológica, consiste em fazer uso das regras de correspondência grafema-fonema. A partir dessa estratégia, articulam-se os componentes ortográfico e fonológico, resultando na identifıcação do significado da palavra.

Outra forma deacionar os três componentes da palavra escrita se apoia no reconhecimento da informação visual por si mesma. Esse tipo de reconhecimento ocorre quando a informação visual ativa o vocabulário mental do leitor, que é composto por um conjunto de informações sobre a ortografia e a pronúncia de uma sequência de letras relacionada a um significado. Tal estratégia de leitura é conhecida como via lexical e é muito usada para ler palavras com as quais o leitor está familiarizado. Essa via permite o acesso direto ao significado da palavra escrita por meio de um reconhecimento automático dos componentes ortográfico e fonológico.

Estudos que focam a leitura oral de palavras evidenciam o uso das duas vias de reconhecimento em situações específicas (COLTHEART, 2005; COLTHEART et al., 2001; PLAUT, 2005; ELLIS, 1995; HILLIS; CARAMAZZA, 1992; para uma revisão da literatura sobre reconhecimento de palavras com crianças falantes do português: LÚCIO; PINHEIRO, 2011). A via lexical é usada quando a tarefa é ler palavras reais e de alta frequência. 
A via fonológica permite a leitura de novas palavras e daquelas com cujas formas escritas - ortografia -, mas não necessariamente com a pronúncia, o leitor tem pouca familiaridade. 0 uso das regras de correspondências grafemafonema na conversão da ortografia em pronúncia da palavra que está sendo lida permite ao leitor o acesso ao significado sem que se faça uso da mediação do contexto. Há evidências de que a via fonológica gera conflitos no reconhecimento da informação visual no nível do fonema quando a palavra é irregular, indicando que a leitura correta de palavras irregulares requer frequentemente o uso da via lexical. A pesquisa de Pinheiro (2006, p. 218), que incluiu também a escrita de palavras, além da leitura, identificou

o uso do processo lexical para a leitura e para a escrita de estímulos familiares e $o$ uso do processo fonológico para a leitura e para a escrita de estímulos não familiares.

O leitor pode ainda fazer uso concomitante das duas formas de acionar os componentes da palavra escrita: a via fonológica e a via lexical. Nesse caso, as duas vias se entrecruzam e a leitura da palavra pode ocorrer guiada pelo monitoramento consciente ou não da utilização das estratégias envolvidas.

No que diz respeito à aquisição da leitura, estudos evidenciam que o leitor iniciante adquire novas e mais eficientes estratégias para realizar o reconhecimento das palavras por meio do desenvolvimento do uso dessas vias. Numa perspectiva evolutiva, Frith (1985, 1990), Morton (1989), Ehri e Wilce (1985) e Ehri (2005a, 2005b) postulam que os leitores iniciantes passariam por estágios de aquisição da leitura.

Para Frith $(1990,1985)$ e Morton (1989), o primeiro deles, conhecido como estágio logográfico, é caracterizado por estratégias de uso de pistas visuais e ambientais para o reconhecimento da palavra escrita. 0 estágio seguinte, chamado de alfabético, é caracterizado pela estratégia baseada na análise das palavras em letras, na associação das letras a 'sons' e na síntese desses 'sons'. Nesse estágio, o tratamento seria sequencial, do começo ao fim da palavra" (MORAIS, 1996, p. 186).

Nele, a criança desenvolveria estratégias relacionadas à via fonológica, ou seja, ela aprende a realizar a decodificação grafofonêmica, usando as operações de análise e síntese. Por último, o estágio ortográfico, caracterizado pelo

reconhecimento instantâneo das partes significativas da palavra (as sílabas e os morfemas, por exemplo), levando em consideração a ordem das letras (contrariamente à estratégia logográfica), mas não seus sons (contrariamente à estratégia alfabética). (MORAIS, 1996, p. 186).

Nesse caso, a criança aprende a realizar a leitura visual direta de palavras com as quais vai se familiarizando ao longo de seu processo de aprendizagem da leitura.

Para Ellis (1995), a combinação das estratégias logográficas e alfabéticas conduz ao desenvolvimento do estágio ortográfico. 0 autor ainda ressalta que os processos do tipo ortográfico e alfabético não se sucedem necessariamente. Eles podem surgir paralelamente e a ordem de aparecimento depende do método de instrução. Morton (1989) e Ellis (1995) acreditam que os três estágios de aquisição da leitura não ocorrem necessariamente por uma sequência baseada no desenvolvimento cronológico e que a leitura competente evolui também pelo desenvolvimento do uso da estratégia de dupla via. No entanto, as teorias sobre a aprendizagem da leitura de palavras têm frequentemente concluído que os leitores iniciantes usam preferencialmente 0 processo fonológico para ler palavras. Salles e Parente (2002, p. 330) concluem, de pesquisa com crianças brasileiras em início de $2^{\mathrm{a}}$ e $3^{\mathrm{a}}$ séries, que 
[...] a rota fonológica parece estar melhor desenvolvida e ser mais amplamente usada pela amostra estudada do que a rota lexical, que está em construção, sugerindo um processo de desenvolvimento das habilidades de leitura.

Essa conclusão é coerente com teoria de Share (1995), que considera ser a via fonológica a estratégia principal para as crianças que estão aprendendo a ler, uma vez que elas ainda estariam construindo o léxico ortográfico na memória.

Para Ehri $(1992,1998)$, os leitores aprendem palavras automaticamente formando conexões entre as letras grafadas - a escrita da palavra - e os sons na pronúncia das palavras. Essas conexões são formadas quando os leitores veem a escrita da palavra - a ortografia -, pronunciam a palavra, distinguem fonemas na pronúncia e reconhecem como os grafemas representam os fonemas nessa palavra. Exposições repetidas às palavras escritas garantiriam essas conexões na memória.

Podemos inferir, então, que as conexões implicadas no processo de reconhecimento das palavras são formadas a partir do conhecimento que os leitores vão adquirindo, ao longo do processo de alfabetização, a respeito do sistema alfabético. 0 conhecimento das correspondências grafema-fonema fornece um sistema mnemônico que contribui para o desenvolvimento dos leitores iniciantes, pois uma vez que o sistema de mapeamento alfabético é conhecido, os leitores podem construir o léxico mental armazenamento das informações ortográficas, semânticas e fonológicas. ${ }^{1}$ Além disso, o conhecimento sobre muitas relações letra-som e padrões ortográficos dá aos leitores expectativas gerais sobre como qualquer palavra escrita pode ser pronunciada e como qualquer palavra pronunciada pode ser escrita.

No entanto, muitas crianças apresentam dificuldade com o processo de mapeamento automático da escrita das palavras e de sua

1- Uma revisão dos estudos sobre modelos de reconhecimento de palavras e de aquisição da leitura e da escrita na área da psicologia cognitiva se encontra em PINHEIRO (2006). pronúncia e podem necessitar de muito mais treino para atingir um nível normal de aprendizagem da leitura pela via lexical (EHRI; SALTMARSH, 1995; REITSMA, 1983). Assim, torna-se necessário buscar indícios sobre as estratégias usadas por elas para a leitura de palavras. A partir da caracterização dessas estratégias poderemos saber em que medida elas impedem a identificação da pronúncia e do significado da palavra escrita pelas crianças.

Com base nessas questões, o presente estudo tem como foco de investigação as estratégias, de reconhecimento de palavras escritas manifestadas por crianças em um teste de leitura. Tal instrumento foi controlado por critérios linguísticos relacionados às propriedades das palavras, tais como a estrutura interna da sílaba e os valores de grafemas independentes e dependentes de contexto na composição das palavras.

\section{Metodologia}

\section{Participantes}

Participaram desta pesquisa 15 alunos, com idade entre 7 e 11 anos, dos $1^{\circ}$ e $2^{\circ}$ ciclos do Ensino Fundamental de uma escola municipal de Belo Horizonte. Esses alunos faziam parte de um projeto de acompanhamento escolar da Secretaria Municipal de Educação - o Projeto de Intervenção Pedagógica em Língua Portuguesa (PIP). O PIP foi criado em 2009 com o objetivo de subsidiar o(a) professor(a) no desenvolvimento de um trabalho pedagógico que tem como foco os alunos com defasagem em leitura e escrita. Sua implementação prevê três eixos de trabalho: a formação dos professores, a elaboração de material didático e a avaliação diagnóstica das capacidades linguísticas desenvolvidas pelos alunos. $\mathrm{Na}$ avaliação intermediária desse programa, realizada no início de julho de 2011, observou-se um grande número de alunos que demonstravam pouco domínio da leitura de palavras e de frases. Os alunos que participaram do teste de leitura 
erraram as questões da avaliação do PIP cujos descritores eram "identificar palavras formadas por sílabas canônicas" e "ler e compreender frases". Outro critério usado na seleção dos alunos foi a frequência tanto no horário regular da escola quanto nas atividades do PIP.

\section{Instrumento}

Para a investigação das estratégias de leitura de palavras pelos alunos, realizou-se um teste de leitura oral de palavras isoladas. ${ }^{2}$ Pinheiro e Rothe-Neves (2001) propõem que, em provas de leitura de palavras, estas devem ser escolhidas pelo critério do efeito de regularidade das correspondências grafema-fonema. 0 instrumento construído para esta pesquisa considerou esse critério, ao qual acrescentou outro: a estrutura silábica das palavras. Assim, o instrumento foi produzido a partir da seleção de 44 palavras, $^{3}$ considerando-se, segundo o primeiro critério, os valores atribuídos aos grafemas na leitura (SCLIAR-CABRAL, 2003):

- Palavras com ocorrência de valores atribuídos aos grafemas independentes e dependentes do contexto escrito:
a) posição (ex.: BARRIGA);
b) grafemas s, r e 1 ao final da sílaba interna (ex.: PORTA - FESTA - ALTURA);
c) nasalização das vogais em final de sílaba interna (ex.: FAZENDA);
d) encontro consonantal na mesma sílaba (ex.: CLARO);
e) valores de dígrafos (ex.: CHUVA);
f) vogal átona em palavras começadas pela sílaba (ex.: ABACATE);
g) encontro vocálico (ex.: BEIJO).

2- Participaram da elaboração e da aplicação do teste de leitura de palavras Adriana Alves Pereira, Maria Eugênia Alves Santos e Sandra Aparecida Colares, coordenadoras e formadoras do Projeto de Intervenção Pedagógica em Língua Portuguesa (PIP) da Secretaria Municipal de Educação de Belo Horizonte.

3- Palavras usadas no teste de leitura: bota, chuva, caderno, macarronada, garoto, pedra, festa, uva, anjo, abacaxi, goleiro, escada, girafa, receita, maçã, convite, chinelo, mesa, guloso, altura, escola, caminho, barriga, pente, beijo, jabuticaba, porta, claro, abacate, foguete, galinha, cadeira, cinema, leque, irmão, poste, palavra, apito, mato, fazenda, onça, sapato, prego, caixa.
E, de acordo com o segundo critério, considerando-se a composição silábica das palavras:

- Palavras compostas apenas por sílabas canônicas (ex.: BOTA).

- Palavras compostas por sílabas canônicas e uma sílaba de outro tipo:

a) CVC (ex.: POSTE);

b) CCV (ex.: PEDRA);

c) V (ex.: APITO);

d) VC (ex.: ESCOLA);

e) CVV (ex.: BEIJO).

\section{Procedimentos}

0 instrumento foi produzido em formato de bloco encadernado, de forma que se manteve a ordem de apresentação das palavras. Assim, foi possível incluir, no início da tarefa, palavras que atendessem a todos os critérios, garantindo a leitura de todos os tipos de palavras selecionadas mesmo se a criança se recusasse a continuar o teste. Cada palavra foi apresentada em uma página em branco, em fonte tipo Arial, tamanho 24, cor preta sobre fundo branco. As crianças responderam ao teste individualmente em uma única sessão, realizada em sala cedida pela direção da escola, em período que variou de 15 a 20 minutos. 0 tempo de permanência de cada palavra foi determinado pela criança, que foi instruída a virar a página do bloco assim que terminasse de ler a palavra. As crianças foram orientadas a ler em voz alta todas as palavras apresentadas no bloco. As respostas foram registradas em gravador, e as gravações foram transcritas em tabelas, seguindo as seguintes orientações:

- A leitura das palavras feita pelos alunos foi transcrita em caixa alta (ex.: BOLA).

- As palavras não lidas pela criança foram identificadas como NL (não leu).

- As falas do aplicador que influenciassem a leitura da criança deveriam ser transcritas (ex.: "0 que é isso? Macarronada?"). Não era necessário transcrever falas como "ótimo", "muito bem" ou "continue assim". 
- Os comentários da criança ao longo da leitura foram considerados relevantes e foram transcritos entre colchetes (ex.: "É um bicho grandão com pescoço assim"; ou "Feseta? Não sei”).

- A segmentação da pronúncia das sílabas foi representada com hífen (ex.: BO-LA).

- 0 alongamento na pronúncia das sílabas foi representado com reticências (ex.: BO...LA).

A categorização das ações de leitura foi definida a partir da descrição das pronúncias das crianças e das categorizações de erros de leitura apresentados em estudos sobre leitura de palavras (SALLES, 2005; PINHEIRO, 2001; VILA et al., 2009).

\section{Resultados}

A análise quantitativa e qualitativa da leitura das crianças no teste de palavras permitiu a identificação de três grupos, caracterizados a partir do domínio e das estratégias de decodi- ficação do sistema de escrita. A tabela a seguir apresenta o número total de ocorrências de cada categoria relativa aos comportamentos de leitura dos grupos. No grupo 1, para ler as palavras apresentadas no teste, os alunos se apoiaram basicamente na identificação de letras. Fazem parte desse grupo os alunos A, B, C, I e M, definidos a partir das ocorrências na categoria C11 (substituição da palavra). No grupo 2, os alunos se apoiaram em estratégias de decodificação para ler as palavras do teste. No entanto, eles demonstraram um domínio parcial das correspondências letra-som. Fazem parte desse grupo os alunos $\mathrm{H}$, J, L, 0 e P, identificados a partir das ocorrências no conjunto das categorias que indicam imprecisão no processo de decodificação (C5, C6, C7, C8, C9). No grupo 3, os alunos leem palavras com bom domínio das correspondências letra-som. Fazem parte desse grupo os alunos D, E, F, G e N, identificados a partir das ocorrências na categoria C1(pronúncia da palavra).

Quadro 1- Estratégias de leitura das crianças

\begin{tabular}{|c|c|c|}
\hline Estratégias de leitura das crianças & & Exemplo \\
\hline CO- Não resposta: a criança não leu a palavra. & ABACAXI & - \\
\hline C1- Pronúncia da palavra. & BOTA & BOTA \\
\hline C2- Pronúncia das unidades silábicas da palavra, seguida da pronúncia da palavra. & BOTA & BO-ТА BОТА \\
\hline C3- Pronúncia das unidades silábicas da palavra. & ABACATE & A-BA-CA-TE \\
\hline C4- Pronúncia de nome das letras da palavra (nomeação de letras). & BOTA & BÊ-0-TÊE-A \\
\hline $\begin{array}{l}\text { C5- Na tentativa de decodificar sílabas não canônicas, a criança pronuncia nome de letras e } \\
\text { unidades silábicas da palavra. }\end{array}$ & FESTA & FE-ESSE-TA \\
\hline C6- Na tentativa de decodificar sílabas não canônicas, a criança acrescenta fonemas à palavra. & CONVITE & CO-NE-VI-TE \\
\hline C7- Na tentativa de decodificar sílabas não canônicas, a criança omite fonemas da palavra. & ESCADA & $\mathrm{E}-\mathrm{CA}-\mathrm{DA}$ \\
\hline $\begin{array}{l}\text { C8- Pronúncia de unidades silábicas atribuindo valor sonoro incorreto a grafemas: a criança } \\
\text { substitui e/ou erra fonema devido ao desconhecimento de regras contextuais da língua } \\
\text { portuguesa. }\end{array}$ & GOLEIRO & JO-LEI-RRO \\
\hline $\begin{array}{l}\text { C9- Na tentativa de decodificar sílabas não canônicas, a criança inverte a combinação de } \\
\text { letras na palavra. }\end{array}$ & FESTA & FE-SE-TA \\
\hline C10- Pronúncia de unidade silábica sem marcar a nasalização. & ONÇA & 0 -ÇA \\
\hline C11.1- Substituição da palavra (observa-se uso de pista visual ou fonológica). & BARRIGA & $\begin{array}{l}\text { BÊ DE BOLA, BOLA, SÓ SE } \\
\text { FOR BOLA. }\end{array}$ \\
\hline C11.2- Substituição da palavra (não é possível observar o critério usado pela criança). & BARRIGA & PETECA \\
\hline C12- Pronúncia de unidades maiores da palavra. & ALTURA & AL-TURA \\
\hline C13- Pronúncia da primeira sílaba seguida da pronúncia correta da palavra. & ESCADA & ES - ESCADA \\
\hline $\begin{array}{l}\text { C14- Ao cometer algum erro de pronúncia, seja no nível da palavra, da sílaba ou do fonema, a } \\
\text { criança revisa a pronúncia da palavra. }\end{array}$ & POSTE & $\begin{array}{l}\text { PORTE, POSTE. POSTE } \\
\text { DE LUZ }\end{array}$ \\
\hline C15- A criança conjuga letras para formar sílabas da palavra. & SAPATO & $\begin{array}{l}\text { ESSE COM A, AS; PÊ COM } \\
\text { A, PA; TÊ COM 0, TO. }\end{array}$ \\
\hline
\end{tabular}


Tabela 1 - Número de ocorrências das categorias relativas aos comportamentos de leitura dos alunos

\begin{tabular}{|c|c|c|c|c|c|c|c|c|c|c|c|c|c|c|c|}
\hline \multirow{2}{*}{$\begin{array}{c}\text { Categorias } \\
\text { do comportamento } \\
\text { de leitura dos alunos }\end{array}$} & \multicolumn{5}{|c|}{ Grupo 1} & \multicolumn{5}{|c|}{ Grupo 2} & \multicolumn{5}{|c|}{ Grupo 3} \\
\hline & $A$ & B & $C$ & I & $M$ & $\mathrm{H}$ & $\mathrm{J}$ & $\mathrm{L}$ & 0 & $P$ & $D$ & $E$ & $\mathrm{~F}$ & G & $\mathrm{N}$ \\
\hline $\mathrm{CO}$ & 2 & 1 & 1 & 1 & 18 & 5 & 24 & 0 & 0 & 28 & 0 & 0 & 0 & 0 & 0 \\
\hline C1 & 0 & 0 & 0 & 2 & 1 & 1 & 0 & 7 & 1 & 0 & 30 & 26 & 38 & 29 & 41 \\
\hline $\mathrm{C} 2$ & 0 & 0 & 0 & 1 & 0 & 6 & 2 & 8 & 21 & 3 & 0 & 1 & 1 & 4 & 0 \\
\hline C3 & 0 & 0 & 0 & 0 & 0 & 0 & 0 & 2 & 3 & 0 & 0 & 9 & 0 & 2 & 0 \\
\hline C4 & 23 & 14 & 3 & 0 & 8 & 0 & 12 & 0 & 0 & 0 & 0 & 0 & 0 & 0 & 0 \\
\hline $\mathrm{C} 5$ & 0 & 0 & 3 & 0 & 0 & 1 & 1 & 0 & 0 & 6 & 0 & 0 & 0 & 0 & 0 \\
\hline C6 & 0 & 0 & 0 & 0 & 0 & 1 & 0 & 7 & 2 & 0 & 0 & 1 & 1 & 2 & 1 \\
\hline $\mathrm{C7}$ & 0 & 0 & 0 & 1 & 0 & 0 & 0 & 4 & 1 & 2 & 1 & 0 & 0 & 0 & 0 \\
\hline $\mathrm{C} 8$ & 0 & 0 & 5 & 1 & 4 & 18 & 11 & 16 & 15 & 8 & 10 & 5 & 3 & 0 & 1 \\
\hline $\mathrm{C9}$ & 0 & 0 & 1 & 0 & 1 & 4 & 1 & 3 & 0 & 2 & 0 & 0 & 0 & 1 & 0 \\
\hline $\mathrm{C} 10$ & 0 & 0 & 0 & 0 & 0 & 0 & 0 & 1 & 1 & 1 & 1 & 0 & 0 & 0 & 0 \\
\hline $\mathrm{C} 11.1$ & 21 & 24 & 29 & 16 & 16 & 14 & 10 & 4 & 3 & 2 & 1 & 1 & 0 & 4 & 0 \\
\hline C11.2 & 20 & 19 & 11 & 23 & 5 & 3 & 3 & 0 & 0 & 1 & 0 & 0 & 0 & 2 & 0 \\
\hline C12 & 0 & 0 & 0 & 0 & 0 & 0 & 1 & 0 & 1 & 0 & 0 & 0 & 1 & 1 & 0 \\
\hline $\mathrm{C} 13$ & 0 & 0 & 0 & 0 & 1 & 1 & 0 & 1 & 0 & 0 & 1 & 0 & 0 & 3 & 0 \\
\hline C14 & 0 & 0 & 0 & 0 & 0 & 4 & 0 & 16 & 7 & 0 & 5 & 7 & 4 & 7 & 3 \\
\hline C15 & 0 & 0 & 1 & 1 & 2 & 3 & 10 & 0 & 0 & 5 & 0 & 0 & 0 & 0 & 0 \\
\hline
\end{tabular}

Fonte: Dados da pesquisa.

\section{Perfil dos grupos de alunos}

\section{Grupo 1}

No gráfico a seguir, pode-se observar que predominam nesse grupo os comportamentos de nomear letras da palavra (C4) e de substituição da palavra apresentada (C11.1 e C11.2).

Como foi dito anteriormente, esse grupo é formado pelos alunos A, B, C, I e M. Um dado que chama a atenção no comportamento de leitura dos alunos A, B e M é a relação positiva entre as ocorrências de nomeação de letras e de suposição da palavra escrita (ver ocorrências C4, C11.1 e C11.2, gráfico 2), sugerindo que a identificação de uma ou duas letras da palavra escrita é um forte indicador no processo de leitura desse subgrupo.

No exame qualitativo de suas leituras, , foi possível observar que, ao fazer a análise da aparência da palavra, primeiro nível de reconhecimento da palavra escrita (COLTHEART, 2005), os alunos supõem a palavra apresentada com foco na identificação da primeira letra e, em alguns casos, na identificação da última letra, como nos exemplos apresentados na tabela 2 .

Além de usarem a mesma estratégia para identificar diferentes palavras que começam com a mesma letra (a identificação da primeira letra), os alunos leem diferentes palavras escritas como uma mesma palavra fonológica. No caso de palavras começadas com a letra G (goleiro, girafa, garoto e galinha), os alunos $\mathrm{A}$ e $\mathrm{M}$ as leem como GATO. 0 mesmo ocorre com palavras começadas com a letra P (pente, porta, poste, palavra), para as quais os alunos atribuem a palavra PATO, e com palavras começadas com C (chuva, cadeira e cinema), lidas como CASA. 
Gráfico 1 - Média das ocorrências das categorias de estratégias de leitura no grupo 1

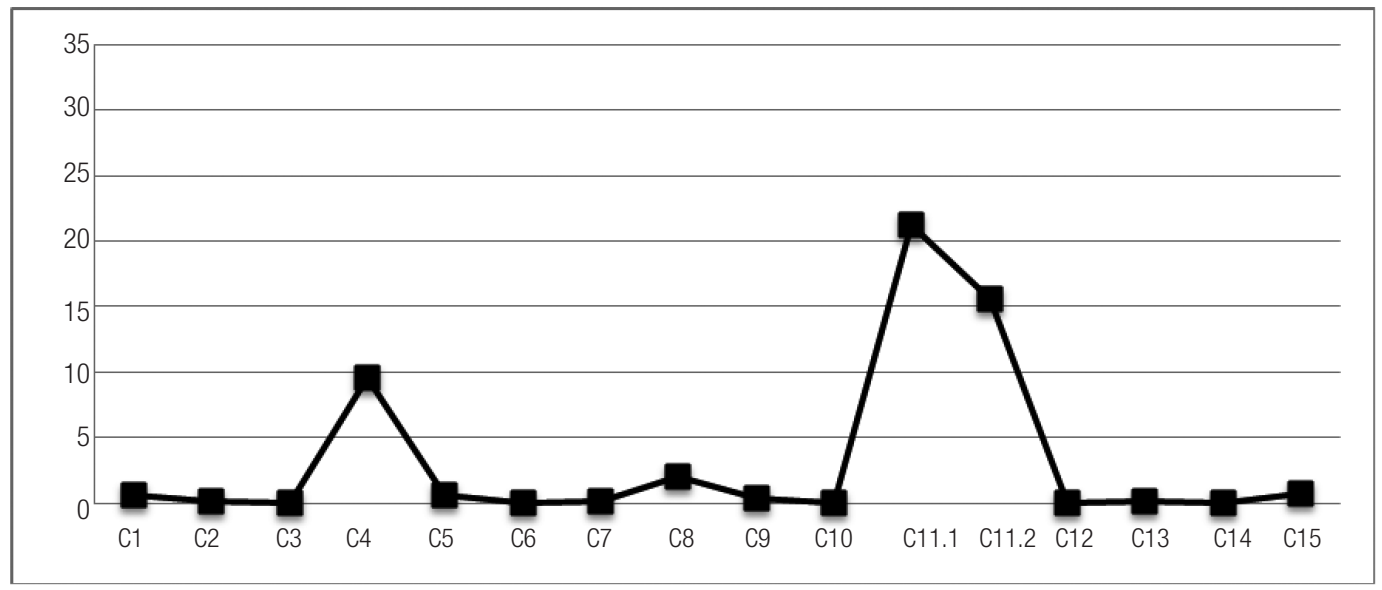

Fonte: Dados da pesquisa.

Gráfico 2 - Ocorrências das categorias de estratégias de leitura dos alunos A, B e M.

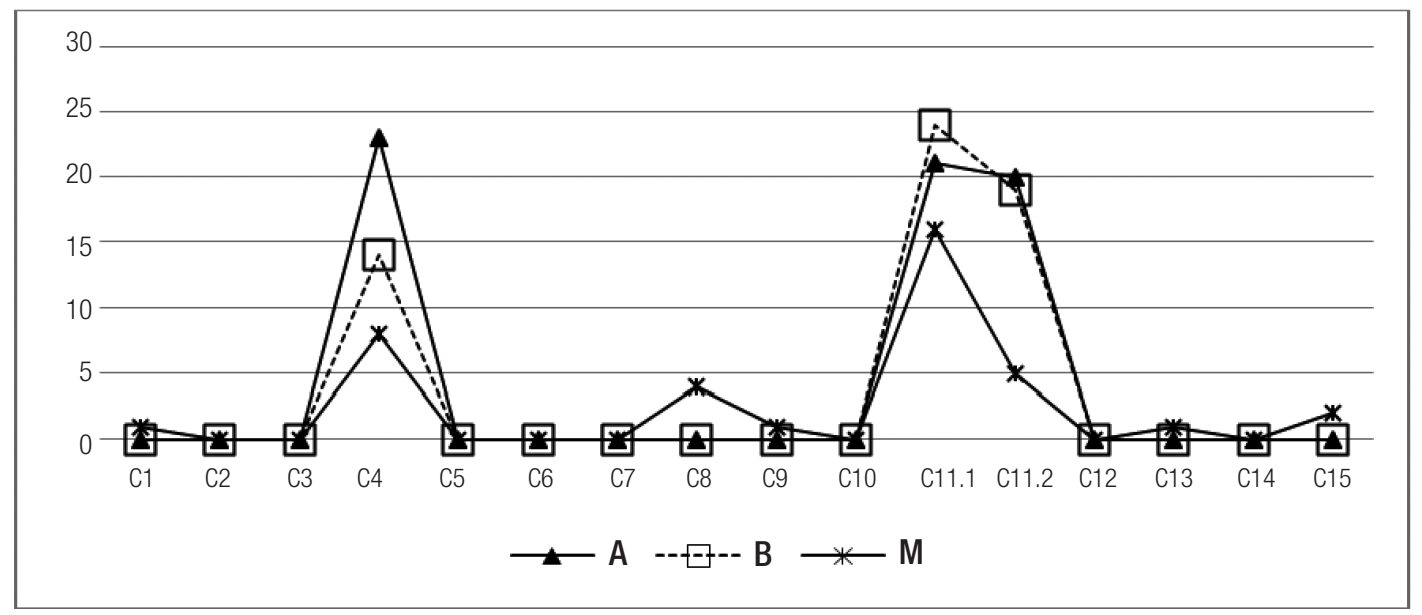

Fonte: Dados da pesquisa.

Tabela 2 - Transcrição da leitura dos alunos do grupo 1

\begin{tabular}{|c|c|c|}
\hline ALUNO & PALAVRA & PRONÚNCIA DA PALAVRA PELA CRIANÇA \\
\hline \multirow{6}{*}{ A } & GOLEIRO & GATO \\
\hline & GIRAFA & GATO \\
\hline & PENTE & PATINHO \\
\hline & PORTA & P DE PATO, PATO DE NOVO \\
\hline & POSTE & PATO \\
\hline & PALAVRA & PATO DE NOVO \\
\hline \multirow{4}{*}{ B } & CHUVA & CASA \\
\hline & CADEIRA & CASA \\
\hline & CINEMA & CASA DE NOVO \\
\hline & ABACAXI & A...B...A...S...A...X...IIGREJA \\
\hline \multirow{2}{*}{ M } & GAROTO & GATO \\
\hline & PEDRA & PATO. O P ESTÁAÍ. \\
\hline
\end{tabular}


Vale ressaltar, ainda, que em muitos casos não foi possível inferir o tipo de pista usada pelos alunos no reconhecimento da palavra escrita.

\section{Grupo 2}

As crianças desse grupo (H, J, L, O e P) realizam o processo de reconhecimento de palavra com base no mecanismo de decodificação (gráfico 3 - média das ocorrências das categorias de leitura). 0 número de ocorrências de pronúncia correta das unidades silábicas da palavra seguida da pronúncia da palavra (C2) sugere que o mecanismo de decodificação ainda está em processo de consolidação para esses alunos. 0 exame de suas estratégias de leitura indica um domínio parcial das correspondências letra-som, evidenciado pelas ocorrências das categorias C5, $\mathrm{C} 6, \mathrm{C} 7$ e C9, que indicam que as crianças cometem mais erros no mecanismo de decodificação de sílabas não canônicas, e pela predominância das ocorrências da categoria C8 (pronúncia de unidades silábicas atribuindo valor sonoro incorreto a grafemas). Vale destacar que nenhuma das ocorrências resultou em pronúncia correta da palavra apresentada, o que indica que os alunos desconhecem muitas relações letra-som.

As ocorrências da categoria de substituição da palavra (C11.1) na leitura das crianças são caracterizadas pelo uso mais constante de pistas fonológicas. Podemos observar a presença significativa da categoria de revisão da leitura (C14), que não aparece no grupo 1 e é um comportamento significativo na leitura dos alunos que compõem o grupo 3.

Gráfico 3 - Média das ocorrências das categorias de leitura no grupo 2

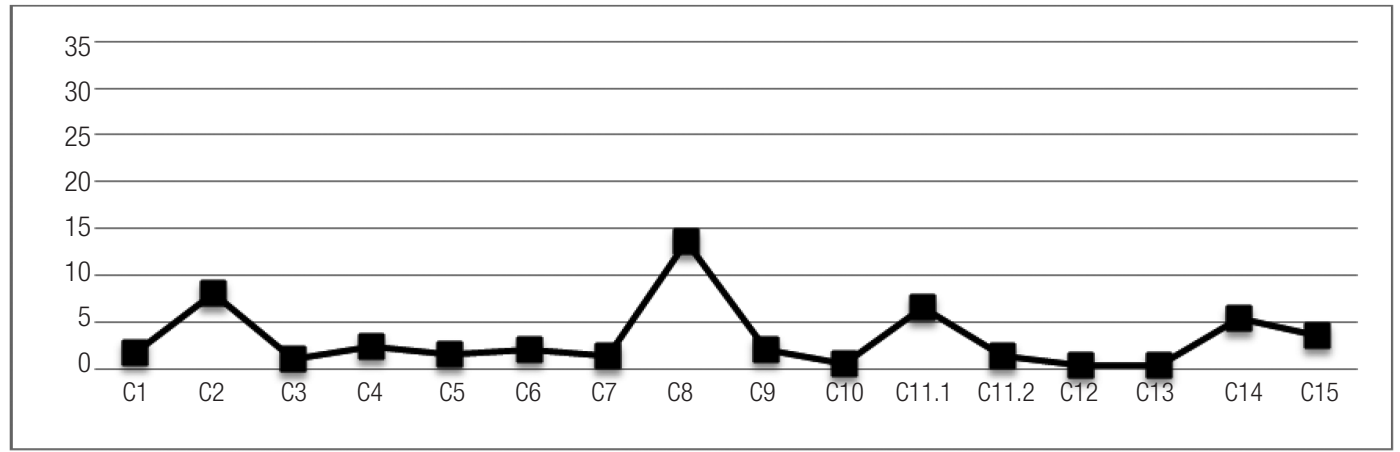

Fonte: Dados da pesquisa.

0 exame dos resultados da leitura das crianças fornece mais evidências sobre o nível de domínio do sistema de escrita do grupo 2. Mesmo acertando mais de 50\% das palavras apresentadas no teste, os alunos L (34 palavras corretas) e 0 (29 palavras corretas) tiveram baixa incidência na categoria $\mathrm{C} 1$ (pronúncia da palavra), que é a categoria definidora do perfil do grupo 3, que lê palavras com bom domínio das correspondências letra-som.

As crianças desse grupo cometeram muito mais erros no mecanismo de decodificação de sílabas não canônicas ( $\mathrm{C} 5, \mathrm{C} 6, \mathrm{C} 7$ e C9). Na tabela a seguir, podemos ver que, em vários momentos, o aluno $\mathrm{P}$ hesita no processo de leitura, demonstrando certo desconforto com as sequências de letras em sílabas não canônicas e dígrafos. Nesses momentos, ele lança mão da estratégia de combinar as letras para formar sílabas, sempre buscando o modelo da sílaba padrão CV. Para ler as palavras FESTA, PEDRA, CONVITE e CHUVA, o aluno pronuncia nome de letras e unidades silábicas da palavra, inverte a combinação de letras e omite fonemas da palavra para chegar a uma sequência fonológica familiar. 
Além disso, o uso dessa estratégia na leitura da palavra CHUVA leva o aluno a pronunciar uma sílaba isolada a partir do nome de uma de suas letras (H). É possível observar ainda que a criança desconhece valores sonoros de grafemas em contextos diferentes.

Tabela 3 - Transcrição da leitura do aluno P (grupo 2)

\begin{tabular}{|c|c|c|c|}
\hline PEDRA & FESTA & CONVITE & CHUVA \\
\hline $\begin{array}{c}\text { C.: PE... PE... PE...DÊ... PE- } \\
\text { DÊ-RRA } \\
\text { A.: Que palavra é essa? } \\
\text { C.: PEDÊRRA }\end{array}$ & $\begin{array}{c}\text { C.: FA-FE-ESSE } \\
\text { C.: FE-FE-TÊ-TA-ESSE-TA-FA } \\
\text { C.: É com FE-ESSE } \\
\text { A.: Isso mesmo, leia de novo. } \\
\text { C.: EFE COM E, FE-ESSE. } \\
\text { A.: Isto. } \\
\text { C.: EFE COM E, FE-TA } \\
\text { C.: FE... FE-TA FE-TA } \\
\text { A.: E o som dessa letra aqui ó? } \\
\text { (Chama atenção para a letra S.) } \\
\text { C.: ES-E-ES-TE-TA } \\
\text { C.: ECÊTA } \\
\text { A.: Você sabe o que significa a } \\
\text { palavra? } \\
\text { C.: Não. }\end{array}$ & $\begin{array}{c}\text { C.: CO-ENE-VÊ COM I, VI- TÊ COM } \\
\text { E, TÉ-NÓ. } \\
\text { C.: Não estou conseguindo, não. } \\
\text { A.: Não? Só mais uma vez. } \\
\text { C.: CO-ENE-VI-TÉ } \\
\text { A.: } 0 \text { que está escrito? } \\
\text { C.: VI-TÉ } \\
\text { A.: E você sabe o que significa? } \\
\text { C.: Não. }\end{array}$ & $\begin{array}{c}\text { C.: C COM A } \\
\text { C.: C COM AGÁ, GA } \\
\text { C.: CU...VA } \\
\text { A.: Que palavra é essa? } \\
\text { C.: U...VA } \\
\text { A.: Fala alto. } \\
\text { C.: U-VA } \\
\text { C.: UVA }\end{array}$ \\
\hline
\end{tabular}

Nota: $\mathrm{C}=$ criança; $\mathrm{A}=$ aplicador

Outro dado importante sobre o processamento da leitura desses alunos é observado nas ocorrências da categoria C8 (pronúncia de unidades silábicas atribuindo valor sonoro incorreto a determinados grafemas), que é predominante no perfil do grupo 2 (ver gráfico 2): quase sempre resultam na pronúncia de pseudopalavras ou de outras palavras (tabela 4). Esse dado indica que os alunos não conseguem acessar a palavra fonológica e seu significado por meio do mecanismo de decodificação devido ao desconhecimento de muitas das correspondências letra-som. Nesse caso, o uso da via fonológica para a leitura de palavras teria pouca eficácia em consequência do pouco domínio que eles têm do sistema ortográfico de escrita.

Dentre os alunos do grupo, vale destacar o perfil de leitor da criança J. As ocorrências de C4 (12), C11.1 (10) e C15 (9) evidenciam uma relação positiva entre os comportamentos de pronunciar nome de letras, de substituição de palavras e da estratégia de aglutinar letras para formar sílabas canônicas. Em nenhuma das ocorrências observou-se uma pronúncia correta da palavra apresentada, o que indica que o aluno desconhece muitas relações letra-som.

Tabela 4 - Relação entre ocorrências da categoria C8 (pronúncia de unidades silábicas atribuindo valor sonoro incorreto a grafemas) e resultado da leitura

\begin{tabular}{|c|c|c|c|c|c|}
\hline \multirow{2}{*}{ ALUNO } & \multirow{2}{*}{ OCORRÊNCIA DE C8 } & \multicolumn{4}{|c|}{ RESULTADO DA LEITURA } \\
\hline & & PC & $\mathrm{PO}$ & PP & NA \\
\hline $\mathrm{H}$ & 18 & 3 & 8 & 7 & - \\
\hline$J$ & 11 & - & 7 & 4 & - \\
\hline 0 & 15 & 6 & 2 & 6 & 1 \\
\hline$P$ & 9 & - & 3 & 4 & 1 \\
\hline
\end{tabular}

Nota: $\mathrm{PC}=$ pronúncia da palavra apresentada

$\mathrm{PO}=$ pronúncia de outra palavra

$\mathrm{PP}=$ pronúncia de pseudopalavra

$\mathrm{NA}=$ não leu a palavra 
Gráfico 4 - Ocorrências das categorias de estratégias de leitura do aluno J

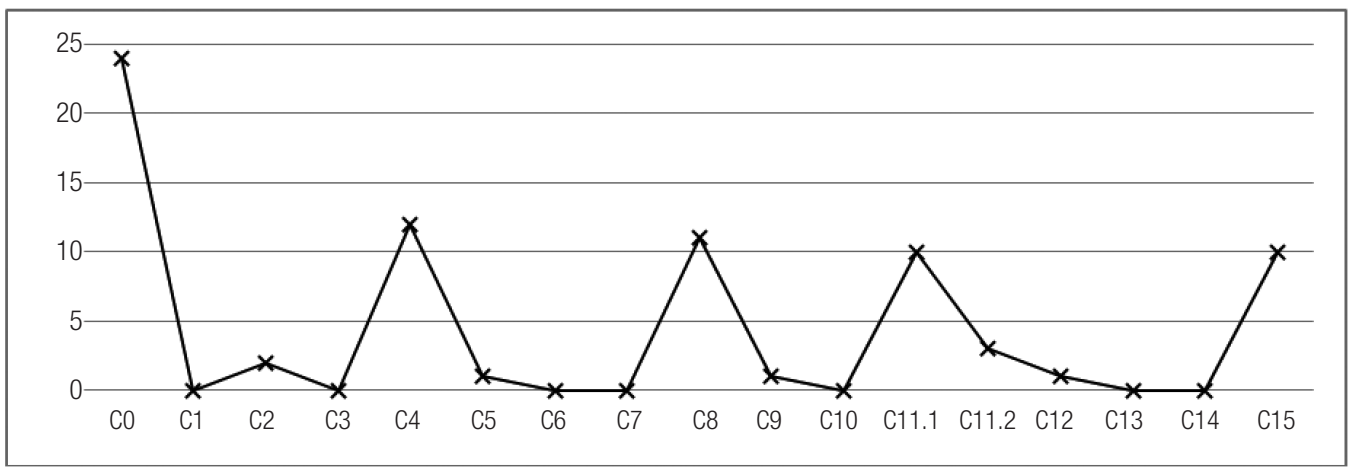

Fonte: Dados da pesquisa.

A estratégia de analisar a sequência de letras da palavra, conjugando pares de C e V para formar sílabas da palavra, foi a mais recorrente na leitura das crianças desse grupo. Na tabela 5 vemos um exemplo de como funciona esse mecanismo, tendo como referência a leitura da palavra BOTA pela criança $\mathrm{P}$.

Tabela 5 - Transcrição da leitura do aluno P (grupo 2) palavra BOTA

(1) C.: BÊ COM 0, BO... TA

A.: Isso, pode falar o que você leu.

(2) C.: BO- NI- TA

A.: lê de novo.

(3) C.: B COM O BO BO... TA

(4) BO-TA

(5) BOTA
Nota: $\mathrm{C}=$ criança

$\mathrm{A}=$ aplicador

Na primeira leitura (1), a criança conjuga as duas primeiras letras da palavra, nomeando-as, e realiza a identificação da primeira sílaba da palavra. A pronúncia da segunda sílaba sugere que a operação foi feita mentalmente, sem necessidade de verbalizar os nomes das letras. $\mathrm{Na}$ segunda leitura (2), pode-se observar que a estratégia não garantiu à criança o acesso à palavra apresentada: ela substitui a palavra, acrescentando uma sílaba medial. Isso sugere que, no momento de realizar a síntese do que foi decodificado, a criança tomou como referência apenas a análise acústica e que essa análise lhe indicou outra palavra começada e terminada pelas sílabas pronunciadas. Ao retomar a leitura, a pedido da aplicadora, a criança realiza o mesmo processo, atendo-se agora à escrita da palavra.

0 gráfico a seguir mostra que esse comportamento (C15 - a criança conjuga letras para formar sílabas da palavra) é pouco comum no grupo 1 e inexistente no grupo 3. Podemos dizer que tal comportamento tem uma relação com o mecanismo de decodificação para as crianças desse grupo.

Gráfico 5 - Média das ocorrências C15 (a criança conjuga letras para formar sílabas da palavra) por grupo de alunos

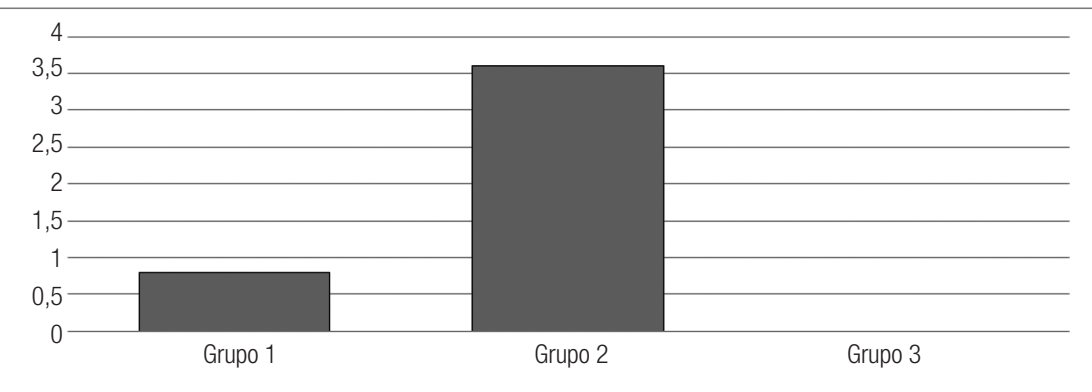

Fonte: Dados da pesquisa. 
sugerindo o desenvolvimento da capacidade de monitoramento de leitura.

0 grupo 3 é composto pelos alunos que

Destacam-se os perfis dos alunos E e G, conseguiram ler palavras sem dificuldades: D, E, F, G e N. Nesse grupo, a ocorrência de C1 (pronúncia da palavra) é muito alta: $\mathrm{D}=30, \mathrm{E}=26, \mathrm{~F}=38, \mathrm{G}=29, \mathrm{~N}=41$. Em geral, os erros cometidos por eles foram revistos, que, mesmo apresentando um maior número de ocorrências da categoria C3 (pronúncia correta das unidades silábicas da palavra), demonstraram, ao longo de todo o teste, compreender as palavras que estavam lendo.

Gráfico 6 - Média das ocorrências das categorias de leitura no grupo 3

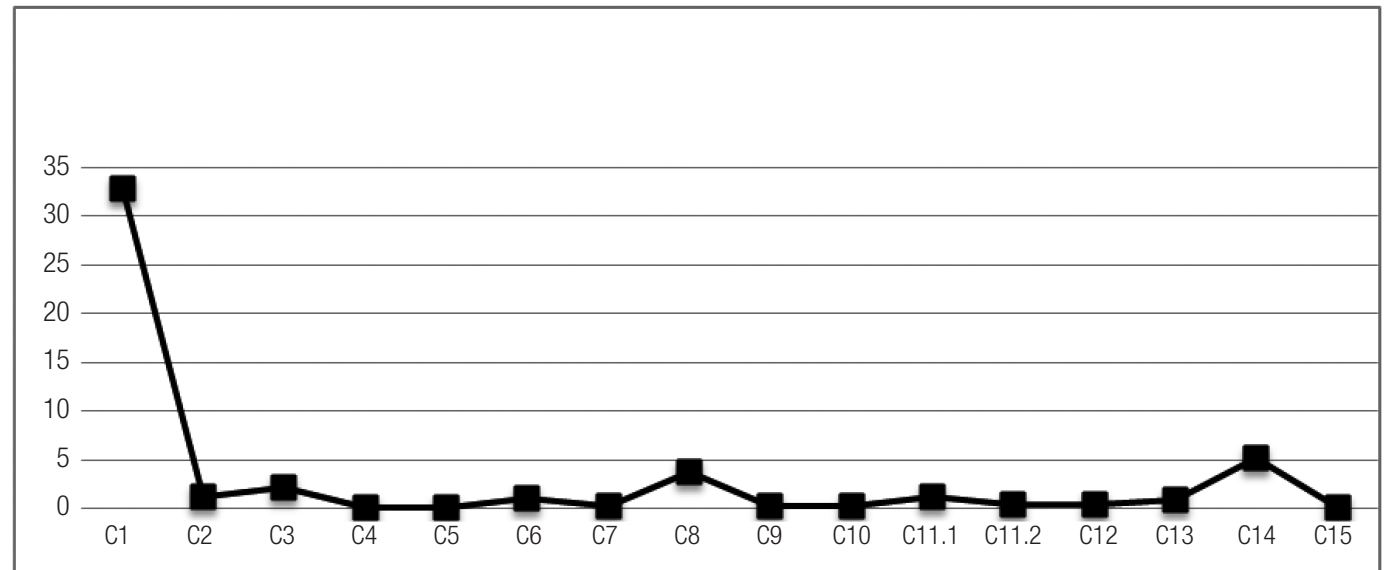

Fonte: Dados da pesquisa.

\section{Discussão}

\section{Relação entre identificar letras e ler palavras}

As estratégias predominantemente utilizadas pelas crianças do grupo 1 (nomeação das letras da palavra e substituição da palavra apresentada) evidenciaram que elas tomam como principal meio para desenvolver seus processos de aquisição da leitura a identificação das letras que compõem a palavra, podendo se basear na nomeação de todas as letras ou priorizar a identificação de uma só letra (em geral, a primeira ou a última letra da palavra). No exame dessas estratégias, encontramos evidências de que a identificação de uma letra e/ou a nomeação das letras da palavra não são suficientes para que as crianças possam ler corretamente a palavra escrita.

Ao que esses dados indicam, a identificação das letras e o conhecimento do nome das letras, sem que se considerem, de forma articulada, outros processos que constituem a aprendizagem das correspondências letra-som, não influenciam significativamente o processo de aquisição da leitura, o que pode se tornar um fator importante para o surgimento das dificuldades enfrentadas por essas crianças em seus processos de alfabetização.

Estudos mostram que, na fase pré-alfabética, as crianças estabelecem conexões não-alfabéticas para ler palavras (EHRI, 1992, 2005a, 2005b). A passagem para a fase alfabética é resultado da aprendizagem das correspondências letra-som, que implica, do ponto de vista do desenvolvimento do aprendiz, o processo de compreensão do princípio alfabético, a familiaridade com as letras e as habilidades relacionadas à consciência fonológica e grafonêmica. Esses três processos não ocorrem isoladamente, como propõem os estudos que buscam clarear tanto a relação entre consciência 
fonológica e alfabetização, quanto a influência do processo de conceitualização da escrita pelas crianças no desenvolvimento de suas capacidades de leitura e escrita.

Os resultados da pesquisa apresentada neste artigo, com base nessa proposição teórica, indicam que o ensino das letras dissociado de um trabalho que promova o desenvolvimento das habilidades de reflexão sobre os sons da língua oral - desenvolvimento da consciência fonológica - e de seus correspondentes na escrita pode dificultar o processo de construção conceitual da criança, não favorecendo a aprendizagem das correspondências letra-som e dificultando o avanço da aquisição da leitura.

\section{0 sistema de análise das correspondências letra-som no uso da via fonológica para a leitura de palavras}

Os resultados da leitura das crianças nos permitiram observar que o mapeamento das correspondências grafema-fonema, segundo nível da via fonológica de reconhecimento da palavra (EHRI, 2005a), é operacionalizado, na leitura das crianças que leem com base no mecanismo de decodificação (grupo 2), por meio da combinação de letras, tendo-se como referência o contexto da estrutura padrão de sílabas (CV). A via fonológica se baseia no uso das regras de correspondências letra-som para a análise da sequência de letras que configuram a palavra a ser lida; assim, para que a leitura seja realizada com sucesso por essa via, não basta combinar letras para que a palavra fonológica correspondente à palavra a ser lida seja identificada. Nesse sistema, são as conexões entre as representações ortográficas e os sons da palavra que dão suporte ao processo de leitura.

0 mecanismo de combinação de letras, tendo como referência o contexto da estrutura padrão de sílabas, pode significar um atraso no processo de alfabetização ou mesmo se tornar um impedimento para a aprendizagem dos alunos quando associado a dois fatores: o pouco conhecimento das regras de correspondências letra-som e a dificuldade desse mecanismo na análise de estruturas silábicas não canônicas. Nos casos em que esses dois fatores estiveram presentes, a criança não chegou à palavra fonológica e, consequentemente, não teve acesso ao significado da palavra apresentada. 0 resultado disso é que o desenvolvimento do léxico ortográfico ficará prejudicado, pois não será possível à criança estabelecer a conexão entre os três componentes da palavra escrita: a palavra fonológica, a palavra ortográfica e a palavra semântica.

Com relação ao domínio parcial das correspondências letra-som, a combinação de letras não garante o acesso à cadeia sonora da palavra fonológica quando as regras contextuais não são consideradas na leitura. Observe-se, por exemplo, as leituras das palavras GOLEIRO, GULOSO e GAROTO, para as quais as crianças pronunciaram, ao final do processo de decodificação, “JOLEIRRO”, “JULOSSO” e “GARROTO”. 0 fato de as crianças operarem com a combinação das letras ( $\mathrm{G}$ com $0, \mathrm{G}$ com U e R com 0) parece fazer com que elas considerem o nome da letra como uma referência para a pronúncia da sílaba identificada ( $\mathrm{G}$ com 0 , JO; R com 0 , RRO, G com U, JU). Nesses casos em que as correspondências fonema-grafema são dependentes do contexto escrito, essa referência torna-se inadequada ao sistema de análise das correspondências letra-som pelo uso da via fonológica para a leitura de palavras.

A dificuldade de leitura pela via fonológica ocorre quando a sílaba a ser decodificada tem uma composição diferente da sílaba canônica. 0 reconhecimento da estrutura interna das sílabas que constituem a escrita de uma palavra permitiria, ao leitor, um acesso mais fácil à representação ortográfica das unidades fonológicas, possibilitando o estabelecimento das correspondências entre o ataque e a rima da sílaba e o grupo de letras em questão. Assim, a desconsideração da estrutura interna da sílaba é um fator de dificuldade para os leitores em processo de alfabetização.

Quando as crianças compreendem que há uma relação entre as letras e os sons das palavras, começam a utilizar esse conhecimento para ler 
palavras. No entanto, sua capacidade, ainda em desenvolvimento, para lidar com a complexidade dos sons da palavra e a aprendizagem incompleta dos padrões ortográficos da língua podem levar a criança a utilizar estratégias para resolver as dificuldades de leitura de sílabas não canônicas, tais como: a omissão da ramificação do ataque em sílabas do tipo CCV; a inversão da direção da leitura em sílabas VC - V seguida de sílaba CV; a inserção de letras na leitura de sílabas do tipo CVC (MONTEIRO, 2007). A superação das dificuldades impostas pela complexidade silábica pode estar no desenvolvimento, por parte das crianças em processo de alfabetização, da capacidade para lidar com a complexidade dos sons da palavra e da consolidação da aprendizagem dos padrões ortográficos da língua. Esse processo passa a ser, então, um fator importante para o avanço das capacidades de leitura, uma vez que é por meio dele que a criança poderá desenvolver o uso da via lexical. Decorre dessa noção a importância do ensino sistemático das regras ortográficas e dos constituintes na conformação da estrutura interna das sílabas ao longo do processo de alfabetização.

\section{Conclusões}

Os dados analisados permitem concluir que as dificuldades dos alunos estão relacionadas a estratégias de leitura de palavras que evidenciam, de um lado, uma dissociação entre conhecimento das letras e desenvolvimento da consciência fonológica e, de outro lado, uma dificuldade de decodificação de estruturas silábicas não canônicas.

Em decorrência disso, a pesquisa sugere a conclusão de que, no processo de aprendizagem da leitura, esses dois eixos precisam ser tratados simultaneamente no ensino, integrando os procedimentos de distinção, segmentação e manipulação de unidades sonoras à análise de seus correspondentes na escrita.

Por outro lado, as estratégias de leitura de palavras reveladas pelas crianças evidenciaram que a conjugação de uma consoante e uma vogal como modelo de mecanismo de decodificação em geral, aprendido no início da alfabetização-, quando associada a um conhecimento parcial das regras de correspondências letra-som e à dificuldade de análise de estruturas silábicas não canônicas, pode provocar atraso no processo de aprendizagem de alunos que enfrentam dificuldades, prejudicando o desenvolvimento do léxico ortográfico. 0 ponto central aqui é que o sistema de escrita parece impor dificuldades à operação desse mecanismo de leitura.

Por conseguinte, a implicação educacional é que é necessário o ensino explícito e sistemático das correspondências letra-som e das estruturas silábicas nas atividades de alfabetização que exploram a palavra e a sílaba como unidades de análise das crianças.

\section{Referências}

ÁVILA, Clara Regina Brandão de et al. Tipologia de erros de leitura de escolares brasileiros considerados bons leitores. Pró-Fono Revista de Atualização Científica, Barueri, v. 21, p. 320-325, out./dez. 2009.

COLTHEART, Max. Modeling reading: the dual-route approach. In: SNOWLING, Margaret J.; HULME, Charles (Eds.). The science of reading: a handbook. Oxford: Blackwell, 2005. p. 6-23.

COLTHEART, Max et al. DRC: A dual route cascaded model of visual word recognition and reading aloud. Psychological Review, v. 108, n. 1, p. 204-256, 2001.

CORSO, Helena Vellinho; SALLES, Jerusa Fumagalli. Relação entre leitura de palavras isoladas e compreensão de leitura textual em crianças. Letras de Hoje, v. 44, n. 3, p. 28-35, 2009. 
EHRI, Linnea C. Reconceptualizing the development of sight word reading and its relationship to recoding. In: GOUGH, Philip B.; EHRI, Linnea C.; TREIMAN, Rebecca (Eds.). Reading acquisition. Hillsdale, NJ: Erlbaum, 1992. p. 107-144.

. Learning to read and learning to spell are one and the same, almost. In: PERFETTI, Charles; RIEBEN, Laurence; FAYOL, Michel (Eds.). Learning to spell. Hillsdale, NJ: Erlbaum, 1998. p. 237-269.

Development of sight word reading: phases and findings. In: SNOWLING, Margaret J.; HULME, Charles (Eds.). The science of reading: a handbook. Malden, MA: Blackwell, 2005a. p. 135-154.

. Learning to read words: theory, findings and issues. Scientific Studies of Reading, v. 9, n. 2, p. 167-188, 2005b.

EHRI, Linnea C.; SALTMARSH, Jill. Beginning readers outperform older disabled readers in learning to read words by sight. Reading and Writing: An Interdisciplinary Journal, v. 7, p. 295-326, 1995.

EHRI, Linnea C.; WILCE, Lee S. Movement into reading: Is the first stage of printed word learning visual or phonetic? Reading Research Quarterly, v. 20, p. 163-179, 1985.

ELLIS, Andrew W. Leitura, escrita e dislexia: uma análise cognitiva. Porto Alegre: Artes Médicas, 1995.

FRITH, Uta. Beneath the surface of developmental dyslexia. In: PATTERSON, Karalyn; MARSHALL, John C.; COLTHEART, Max (Eds.). Surface dyslexia: neuropsychological and cognitive studies of phonological reading. London: Lawrence Erlbaum, 1985.

. Dyslexia as a developmental disorder of language. Londres: MRC, Cognitive Development Unit, 1990.

HARRIS, Theodore L.; HODGES, Richard E. (Eds.). The literacy dictionary: the vocabulary of reading and writing. Newark, DE: International Reading Association, 1995.

HILLIS, Argye E.; CARAMAZZA, Alfonso. The reading process and its disorders. In: MARGOLIN, David I. (Org.). Cognitive neuropsychology in clinical practice. New York, Oxford: Oxford University Press, 1992. p. 229-261.

LÚCIO, Patrícia Silva; PINHEIRO, Ângela Maria Vieira. Vinte anos de estudo sobre o reconhecimento de palavras em crianças falantes do português: uma revisão de literatura. Psicologia: Reflexão e Crítica, v. 24, n. 1, p. 170-179, 2011.

MONTEIRO, Sara Mourão. 0 processo de aquisição da leitura no contexto escolar por alfabetizandos considerados portadores de dificuldades de aprendizagem. Tese (Doutorado em Educação) - Universidade Federal de Minas Gerais, Belo Horizonte, 2007.

MORAIS, José. A arte de ler. São Paulo: Editora da Unesp, 1996.

MORTON, John. An information-processing account of reading acquisition. In: GALABURDA, Albert M. (Org.). From reading to neurons: issues in the biology of language and cognition. Cambridge: The MIT Press, 1989. p. 43-66.

PIKULSKI, John J.; CHARD, David J. Fluency: bridge between decoding and reading comprehension. The Reading Teacher, v. 58, p. 510-519, 2005.

PINHEIRO, Ângela Maria V. Heterogeneidade entre leitores julgados competentes pelas professoras. Psicologia: Reflexão e Crítica, v. 14, n. 3 , p. 537-551, 2001.

. Leitura e escrita: uma abordagem cognitiva. 2. ed. Campinas: Livro Pleno, 2006.

PINHEIRO, Ângela Maria V.; ROTHE-NEVES, Rui. Avaliação cognitiva de leitura e escrita: as tarefas de leitura em voz alta e ditado. Psicologia: Reflexão e Crítica, v. 14, n. 2, p. 399-408, 2001.

PLAUT, David. Connectionist approaches to reading. In: SNOWLING, Margaret; HUME, Charles (Eds.). The science of reading: a handbook. Oxford: Blackwell, 2005. p. 24-38. 
REITSMA, Pieter. Printed word learning in beginning readers. Journal of Experimental Child Psychology, v. 36, p. 321-339, 1983. SALLES, Jerusa Fumagalli de. Habilidades e dificuldades de leitura e escrita em crianças de $2^{\mathrm{a}}$ série: abordagem neuropsicológica cognitiva. Tese (Doutorado em Psicologia do Desenvolvimento) - Universidade Federal do Rio Grande do Sul, Porto Alegre, 2005.

SALLES, Jerusa Fumagalli de; PARENTE, Maria Alice M. Pimenta. Processos cognitivos na leitura de palavras em crianças: relações com compreensão e tempo de leitura. Psicologia: Reflexão e Crítica, v. 15, n. 2, p. 321-331, 2002.

SAMUELS, S. Jay. Toward a model of reading fluency. In: SAMUELS, S. Jay; FARSTRUP, Alan E. (Eds.). What reasearch has to say about fluency instruction. USA: Reading Association, 2006. p. 24-46.

SCLIAR-CABRAL, Leonor. Guia prático de alfabetização, baseado em princípios do sistema alfabético do português do Brasil. São Paulo: Contexto, 2003.

SHARE, David L. Phonological recoding and self-teaching: sine qua non of reading acquisition. Cognition, v. 55, p. 151-218, 1995.

Recebido em: 30.11.2012.

Aprovado em: 27.06.2013

Sara Mourão Monteiro é doutora em Educação, professora adjunta da Faculdade de Educação da Universidade Federal de Minas Gerais (UFMG) e pesquisadora do Centro de Alfabetização, Leitura e Escrita (CEALE).

Magda Soares é doutora e livre-docente em Educação e professora titular emérita da Faculdade de Educação da Universidade Federal de Minas Gerais (UFMG). 